\title{
Algorithm for searching out similar ships within expert system of computer aided preliminary design of ship power plant
}

\author{
Maria Meler-Kapcia, Ph. D. \\ Gdansk University of Technology
}

\begin{abstract}
This paper presents an algorithm for searching out similar ships, implemented in a hybrid system for aiding preliminary design of ship power plant, based on new similarity functions as well as those adapted from literature sources. For searching out similar ships a multicriterial optimization method of weighed profits was applied.
\end{abstract}

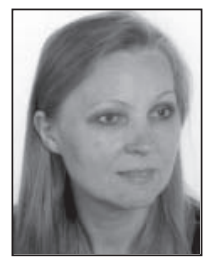

Keywords: artificial intelligence, neural networks, expert systems, similarity functions,

CBR method, multi-criterial optimization, ship design aiding

\section{INTRODUCTION}

The elaborated algorithm of searching out similar ships was implemented in a hybrid system of aiding preliminary design of ship power plant with application of selected tools of artificial intelligence such as: Exsys Developer expert system with applied fuzzy logic. Access relational database as well as artificial neural network of back-propagation of errors. It is intended for aiding preliminary ship design process in which designs of similar existing ships are as a rule used.

To this end, the algorithm for searching out similar ships on the basis of introduced similarity functions (rectangular, trapezoidal, triangular, Gaussian) and those adopted from literature sources (that with lower limit, identity test, and fuzzy logic), was elaborated. For searching out similar ships a multi-criterial optimization method of weighing profits was applied.

Models for multi-criterial assessment of design solutions should be described by means of functions containing main ship design parameters.

If it is given the n-dimensional vector of searched parameters, $\mathrm{x}$ :

$$
\mathrm{x}=\left[\mathrm{x}_{1}, \mathrm{x}_{2}, \ldots \mathrm{x}_{\mathrm{n}}\right]^{\mathrm{T}} \in \mathrm{R}^{\mathrm{n}}, \mathrm{n} \in \mathrm{N}
$$

which is assessed according to the m-dimensional vector of criteria (objective functions), $\mathrm{f}(\mathrm{x})$ :

$$
\mathrm{f}(\mathrm{x})=\left[\mathrm{f}_{1}(\mathrm{x}), \mathrm{f}_{2}(\mathrm{x}), \ldots \mathrm{f}_{\mathrm{m}}(\mathrm{x})\right]^{\mathrm{T}} \in \mathrm{R}^{\mathrm{m}}, \mathrm{m} \in \mathrm{N}
$$

and under assumption that the coordinates of the criterial vector are profit functions, then the multi-criterial optimization problem can be defined as the task of multi-criterial maximization of the profit vector:

$$
\max _{x} f(x)
$$

In the optimum design process the following decisions can be taken:

- to select one solution and assume it the best

$\rightarrow$ to select a subset of solutions out of the set of optimum solutions

D to rank all solutions in the order from the best to the worst, i.e. to made their ranking list.

The multi-criterial optimization methods can be divided into:

$>$ classical ones

ranking ones.

The classical methods consist in integration of many criteria into one. Among other, the weighed criteria method belongs to the classical multi-criterial optimization methods.

The weighed criteria method consists in reducing the multi-criterial optimization to that one-criterial by introducing a substitute criterion in the form of the weighed sum of criteria:

$$
\mathrm{Z}=\sum_{\mathrm{q}=1}^{\mathrm{M}}\left[\mathrm{w}_{\mathrm{q}} \cdot \mathrm{f}_{\mathrm{q}}(\mathrm{X})\right] \rightarrow \mathrm{MIN}
$$

where:

$$
\begin{aligned}
& 0 \leq \mathrm{w}_{\mathrm{q}} \leq 1 \\
& \sum_{\mathrm{q}=1}^{\mathrm{M}} \mathrm{w}_{\mathrm{q}}=1
\end{aligned}
$$

In the method a problem is to select a priori values of weighing factors of particular criteria, that may lead to differring solutions. 


\section{DESCRIPTION OF THE ALGORITHM FOR SEARCHING OUT SIMILAR SHIPS}

The problem of searching out similar ships can be reduced to the task of multi-criterial optimization. Out of the available methods of solving multi-criterial optimization tasks the classical method of weighed profits was implemented. In the method the coordinates of vector of profits (partial similarities) are aggregated into one function of profits (summary similarity) by means of the following transformation:

$$
\mathrm{pg}(\text { is })=\mathrm{w} * \mathrm{pcz}(\text { is })
$$

where:

pg(is) - summary similarity

pcz(is) - vector of partial similarities

$\mathrm{W}-$ normalized row vector of weighing factors: $\left[\mathrm{w}_{1} \mathrm{w}_{2} . . \mathrm{w}_{\text {ip }} \ldots \mathrm{w}_{\mathrm{lp}}\right], \mathrm{w}_{\mathrm{ip}} \in<0.1>$ and $\sum \mathrm{w}_{\mathrm{ip}}=1$

is $\quad-$ ship identifier

ip $\quad-$ index of ship parameter

lp $\quad-$ number of ship parameters

* $\quad$ - scalar product

The process of searching out similar ships begins from the determination of:

is parameters (database fields) of designed ship

is lower and upper limits and standard parameters: $\left(\mathrm{P}_{\mathrm{G}}, \mathrm{P}_{\mathrm{D}}, \mathrm{O}_{\mathrm{G}}, \mathrm{O}_{\mathrm{D}}\right)$.

The searching out is realized on the basis of ship parameters considered as input data to the algorithm. Number of the parameters is limited and may be contained in the range from one to a few dozen.

Fig. 2 presents the example schematic diagram of the algorithm for searching out similar ships, in which the following blocks can be distinguished:

$\Rightarrow$ block of similarity functions (rectangular, trapezoidal, triangular, Gaussian or that with lower limit)

$\Rightarrow$ block of threshold functions which determine minimum similarity limit for a given phase of searching process. Threshold value should be greater than zero and smaller than $1,(8)$

$\Rightarrow$ block of products for realization of the weighed sum $\mathrm{pg}($ is $)=\mathrm{w} * \mathrm{pcz}($ is $)$

$\Rightarrow$ block of settings of similarity function parameters: kind of function, $\mathrm{S}(\mathrm{x})$, upper standard deviation $\left(\mathrm{O}_{\mathrm{G}}\right)$ and lower one $\left(\mathrm{O}_{\mathrm{D}}\right)$, lower limit deviation $\left(\mathrm{P}_{\mathrm{D}}\right)$, and upper one $\left(\mathrm{P}_{\mathrm{G}}\right)$

$\Rightarrow$ block of settings of the thresholds $\operatorname{Pr}[\mathrm{ip}]$ and output control. In the case when any of the ship parameters is of a value below the assumed threshold then the considered ship is neglected

$\Rightarrow$ block of determination of vector of parameter weighing factors.

Between values of partial similarities and the block of setting threshold values a feedback mechanism is applied to limit number of found similar events (ships) having too low similarity.

The elaborated algorithm for searching out similar ships was based on the application of the following similarity functions:

\section{- Rectangular function}

In the case of finding the ships identical with the designed ship, design solutions of one of them are used for the design project under elaboration. The function is presented in Fig.1a. If in the database is no identical ships then other functions are applied to calculate similarity in the following sequence: trapezoidal, triangular, Gaussian, or that with lower limit - for numerical parameters, as well as the identity test (zero-one method) - for text parameters (such as e.g.: (type of main engine, name of its producer or type of screw propeller).

\section{- Trapezoidal function}

For less stringent design requirements the algorithm can be started by assuming the trapezoidal function as an initial similarity function, shown in Fig. 1c, where: $\left(\mathrm{P}_{\mathrm{G}}-\mathrm{O}_{\mathrm{G}}\right)>\left(\mathrm{O}_{\mathrm{D}}-\mathrm{P}_{\mathrm{D}}\right)$. The similarity in the interval from $\mathrm{O}_{\mathrm{D}}$ to $\mathrm{O}_{\mathrm{G}}$ is assumed equal 1 , and linearly changing - below and over the interval.

\section{- Triangular function}

The trapezoidal function can be transformed to the triangular one, either symmetrical or non-symmetrical $\left(\mathrm{P}_{\mathrm{G}}-\mathrm{p}_{\mathrm{p}}\right)>\left(\mathrm{p}_{\mathrm{p}}-\mathrm{P}_{\mathrm{D}}\right)$, by assuming values of standard deviations equal zero, see Fig.1b. In the diagrams of trapezoidal and triangular functions different values of upper and lower deviations are assumed in order to show possible choice of asymmetry of the functions in question.

\section{- Gaussian function}

The Gaussian function, in which asymmetry is also applied, provides the widest range of searching similar objects. It is presented in Fig. 1d.

\section{- Threshold function}

It determines a minimum limit of similarity for a given phase of searching out process. Value of the threshold $\mathrm{Pr}$ should be greater than zero and smaller than 1 (Fig. 1f).

$$
\mathrm{H}\left(\mathrm{p}_{\mathrm{z}}\right)=\mathrm{p}_{\mathrm{z}}^{*} \mathrm{H}\left(\mathrm{p}_{\mathrm{z}}-\mathrm{Pr}\right)
$$

where:
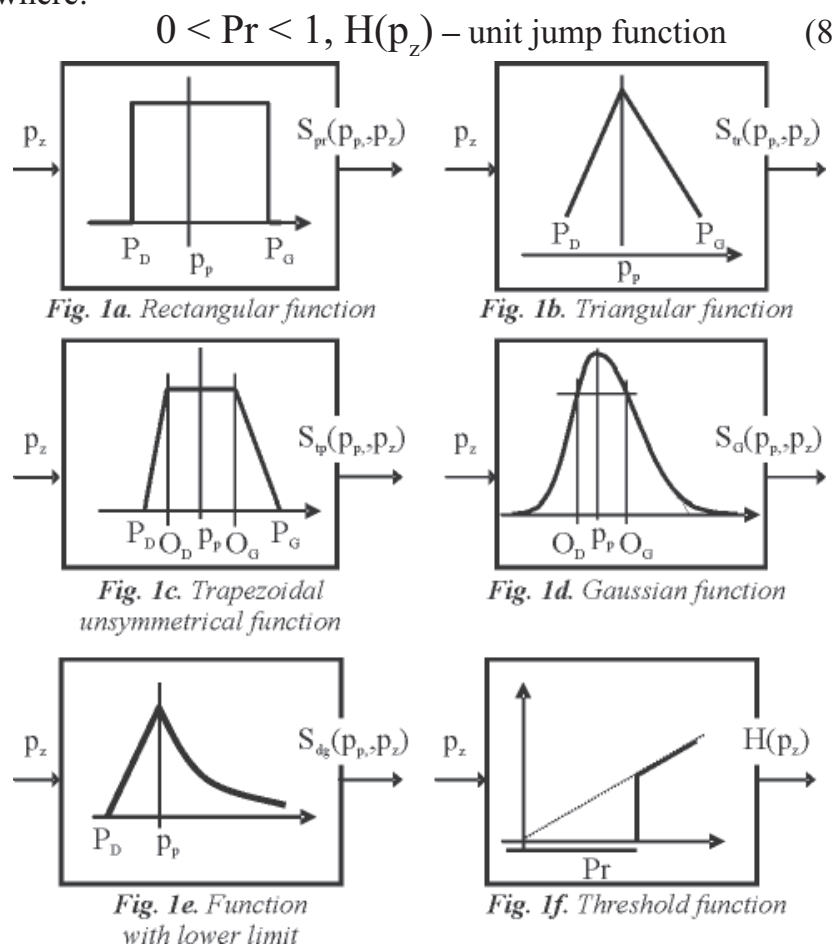

Fig. 1. Functions used in the algorithm for calculation of similarity of ships

where:

$p_{p}-$ value of designed ship parameter

$p_{z}-$ current value of existing ship

$P_{D}-$ lower limit of value of the parameter $p_{p}$

$\mathrm{P}_{\mathrm{G}}-$ upper limit of value of the parameter $\mathrm{p}_{\mathrm{p}}$

$\mathrm{O}_{\mathrm{D}}$ - lower standard parameter

$\mathrm{O}_{\mathrm{G}}-$ upper standard parameter 
as well as percentage values of deviations of these parameters:

$\Delta \mathrm{P}_{\mathrm{D}}=\left(\mathrm{p}_{\mathrm{p}}-\mathrm{P}_{\mathrm{D}}\right) / \mathrm{p}_{\mathrm{p}} * 100 \%-$ lower limit deviation,

$\Delta \mathrm{P}_{\mathrm{G}}=\left(\mathrm{p}_{\mathrm{p}}-\mathrm{P}_{\mathrm{G}}\right) / \mathrm{p}_{\mathrm{p}} * 100 \%-$ upper limit deviation,

$\Delta \mathrm{O}_{\mathrm{D}}^{\mathrm{G}}=\left(\mathrm{p}_{\mathrm{p}}-\mathrm{O}_{\mathrm{D}}\right) / \mathrm{p}_{\mathrm{p}} * 100 \%$ - lower standard deviation,

$\Delta \mathrm{O}_{\mathrm{G}}=\left(\mathrm{p}_{\mathrm{p}}-\mathrm{O}_{\mathrm{G}}\right) / \mathrm{p}_{\mathrm{p}} * 100 \%$ - upper standard deviation.

The searching out of a similar ship is performed in the following phases:

$\downarrow$ Ships identical with the designed one are searched out by using the rectangular similarity function. If the set of similar ships is empty the phase 2 is realized.

$*$ In the case of no identical ships the searching out process by using the triangular similarity function with decreased threshold values of threshold functions, is triggered. This can result in: the empty set of similar ships (then the phase 3 is realized) or the set containing from one to many similar ships.

* In the case of no similar ships the searching out process based on the trapezoidal similarity function is realized. If many similar ships are found then the threshold values of threshold functions are increased and the searching out process is repeated so as to reduce number of found ships down to a few at the most.

\& When no similar ships are found the Gaussian similarity function is applied for further calculations and if it does not provide a result the phase 5 is realized.

$\$$ The similarity function with lower limit is applied. It is characterized by the feature that in searching out similar ships it takes into account broader and broader range of values of ship parameters over design value.

In the successive phases of the algorithm the similarity functions are called in the same sequence, shown in Fig. 2.

The above specified phases of searching out process are initiated automatically, however the designer is allowed to interfere in each of them.

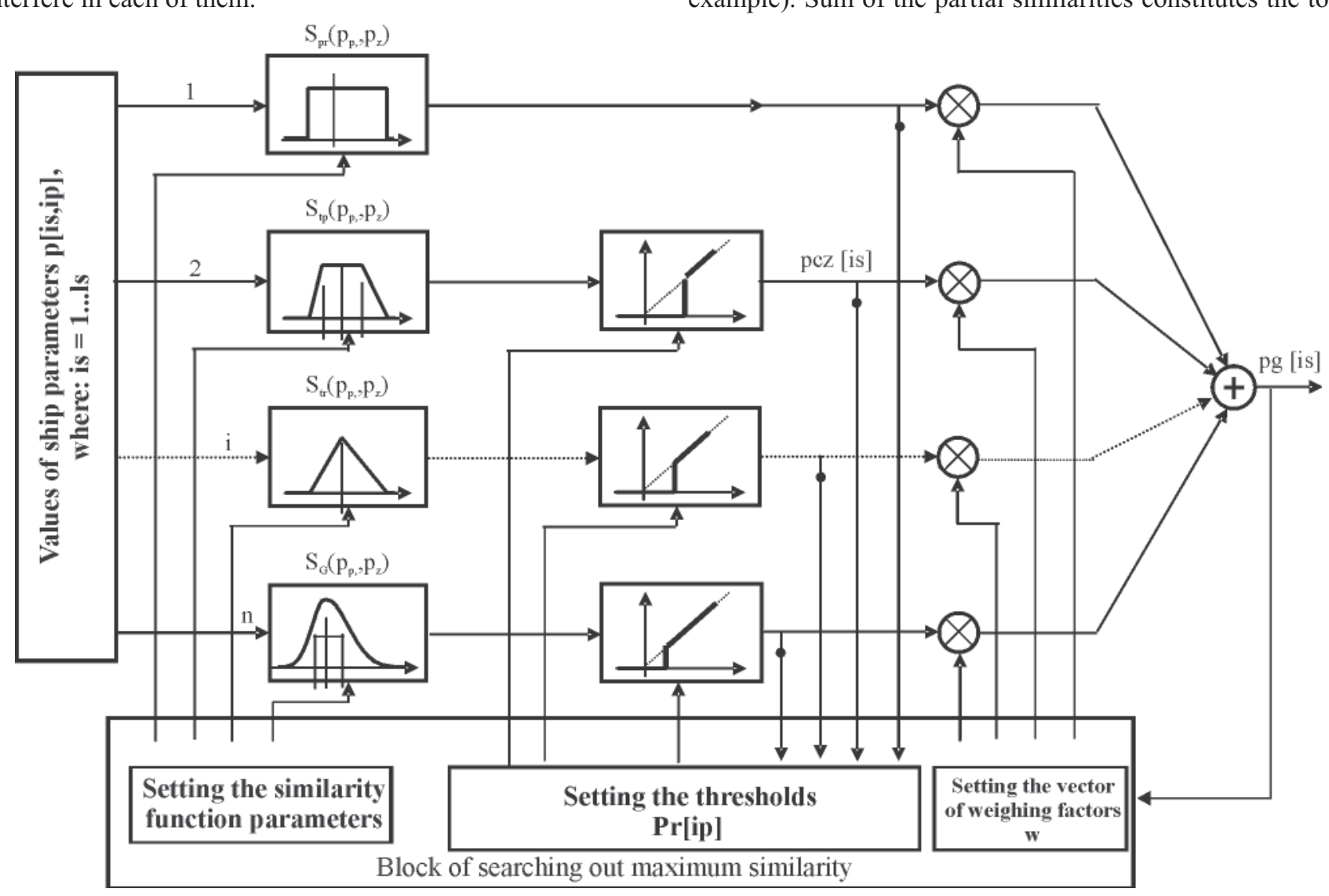

Fig. 3. Schematic diagram of the algorithm for searching out similar ships
The schematic diagram of the algorithm is presented in Fig. 3 .

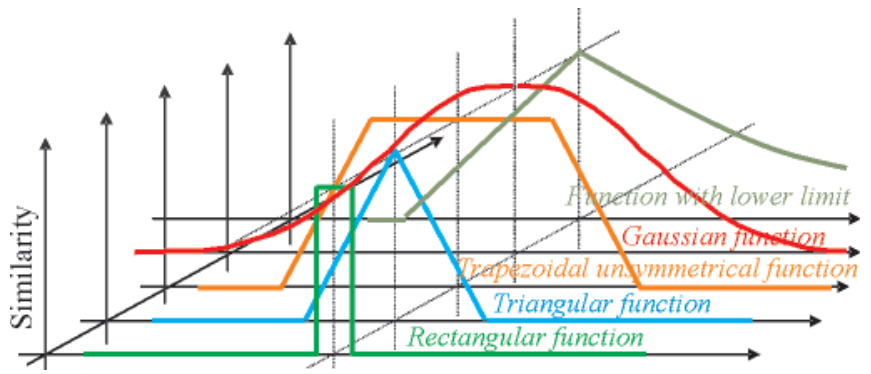

Fig. 2. Ship similarity functions called in successive phases of the ship searching out algorithm

\section{IMPLEMENTATION OF THE ALGORITHM FOR SEARCHING OUT SIMILAR SHIPS}

The main function of the elaborated algorithm is to search similar ships out of the database. Number of such ships can be very different: from one to even a few dozen. The number results from applied similarity function as well as from size and content of the database and assumed design parameters such as ranges and thresholds of similarity function. The parameters are determined in advance by the designer before initiation of the process of searching out similar ships. Next, name of database file and designed ship's data should be put in. Then the process of calculation of similarity of particular parameters, such as main engine's power and its rotational speed, and of similarity of threshold function, is started. Final similarity of a parameter is obtained by calculating the weighed similarity of the parameter. The calculation process of weighed similarities of particular parameters is ended when all introduced ship parameters are taken into account, and their weighed sum constitutes a partial similarity (of main propulsion system, for example). Sum of the partial similarities constitutes the total 
weighed similarity of entire ship, on the basis of which similar ships are searched out.

For practical reasons it has been assumed that in the algorithm of searching out similar ships percentage values of deviations of parameters of most similar ships, from their input values, as well as $p_{p}$ value, are applied, as shown in Tab. 2 . To obtain real values of the parameters the following formulae are used:

$$
\begin{aligned}
& \mathrm{P}_{\mathrm{D}}=\mathrm{p}_{\mathrm{p}}-\frac{\mathrm{p}_{\mathrm{p}} * \Delta \mathrm{P}_{\mathrm{D}}}{100} \\
& \mathrm{O}_{\mathrm{D}}=\mathrm{p}_{\mathrm{p}}-\frac{\mathrm{p}_{\mathrm{p}} * \Delta \mathrm{O}_{\mathrm{D}}}{100} \\
& \mathrm{P}_{\mathrm{G}}=\mathrm{p}_{\mathrm{p}}+\frac{\mathrm{p}_{\mathrm{p}} * \Delta \mathrm{P}_{\mathrm{G}}}{100} \\
& \mathrm{O}_{\mathrm{G}}=\mathrm{p}_{\mathrm{p}}+\frac{\mathrm{p}_{\mathrm{p}} * \Delta \mathrm{O}_{\mathrm{G}}}{100}
\end{aligned}
$$

where:

$\Delta \mathrm{P}_{\mathrm{D}}=\left(\mathrm{p}_{\mathrm{p}}-\mathrm{P}_{\mathrm{D}}\right) / \mathrm{p}_{\mathrm{p}} * 100 \%-$ lower limit deviation, $\Delta \mathrm{P}_{\mathrm{G}}=\left(\mathrm{p}_{\mathrm{p}}-\mathrm{P}_{\mathrm{G}}\right) / \mathrm{p}_{\mathrm{p}} * 100 \%$ - upper limit deviation, $\Delta \mathrm{O}_{\mathrm{D}}=\left(\mathrm{p}_{\mathrm{p}}-\mathrm{O}_{\mathrm{D}}\right) / \mathrm{p}_{\mathrm{p}} * 100 \%$ - lower standard deviation, $\Delta \mathrm{O}_{\mathrm{G}}=\left(\mathrm{p}_{\mathrm{p}}-\mathrm{O}_{\mathrm{G}}\right) / \mathrm{p}_{\mathrm{p}} * 100 \%$ - upper standard deviation.

In Tab. 1 example values of more important parameters of the main propulsion system of designed ship are given.

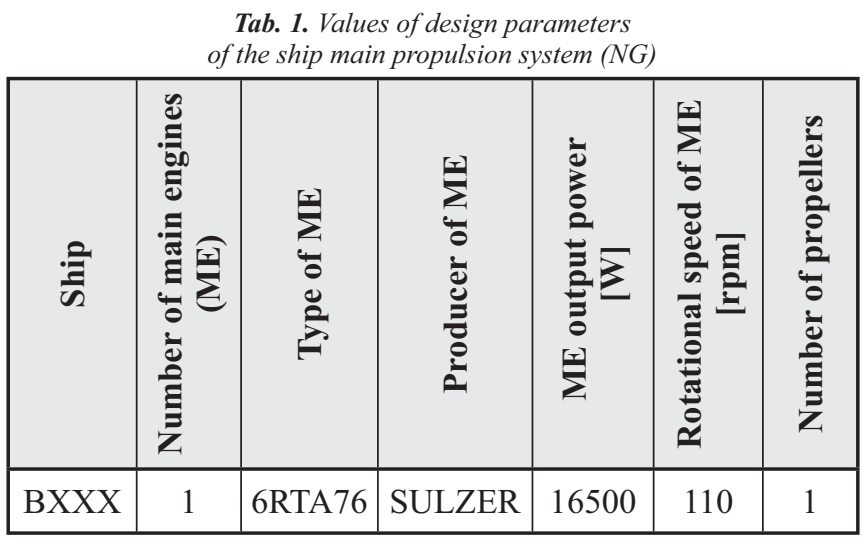

The elaborated functions for similarity calculation are presented and tested on the basis of two numerical parameters, i.e. ME output power and rotational speed. The analysis was performed for example values of the limit and standard deviations of the parameters as well as example values of their weighing factors, given in Tab. 2;

\begin{tabular}{|c|c|c|c|c|c|}
\hline 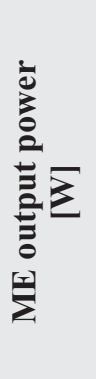 & 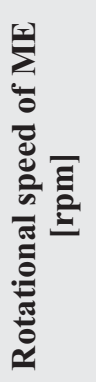 & 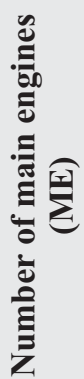 & 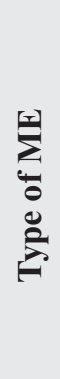 & 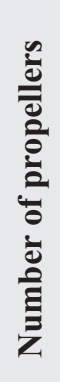 & 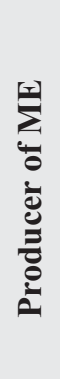 \\
\hline 0.3 & 0.2 & 0.2 & 0.1 & 0.1 & 0.1 \\
\hline
\end{tabular}

Tab. 2. Values of weighing factors of design parameters of main propulsion system $(N G)$

(Variant 1)

as well as the limit and standard deviations, given in Tab. 3 .
Tab. 3. Values of limit and standard deviations of design parameters of main propulsion system $(N G)$

\begin{tabular}{|c|c|c|c|c|c|}
\hline Parameter & $\mathbf{P}_{\mathbf{p}}$ & $\Delta \mathbf{P}_{\mathbf{D}} \%$ & $\Delta \mathbf{O}_{\mathbf{D}} \%$ & $\Delta \mathbf{P}_{\mathbf{G}} \%$ & $\Delta \mathbf{O}_{\mathbf{G}} \%$ \\
\hline Power [kW] & 16500 & 20 & 10 & 20 & 10 \\
\hline $\begin{array}{c}\text { Rot.speed } \\
\text { rpm/min] }\end{array}$ & 110 & 20 & 10 & 20 & 10 \\
\hline
\end{tabular}

The summary similarities calculated by means of the database application according to particular functions, for assumed values of weighing factors, limit and standard

\begin{tabular}{|c|c|c|c|c|c|c|}
\hline$\frac{\varrho}{\sqrt{n}}$ & $\begin{array}{l}\sum \\
\sum \\
0 \\
0 \\
0\end{array}$ & 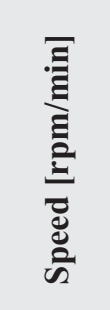 & 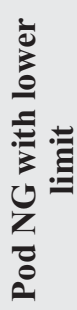 & 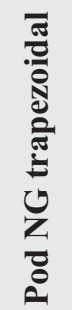 & 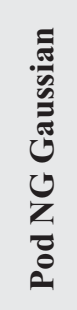 & 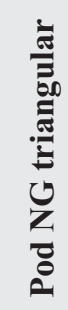 \\
\hline 124 & 18160.00 & 110.00 & 0.47 & 0.50 & 0.31 & 0.35 \\
\hline 41 & 18160.00 & 110.00 & 0.47 & 0.50 & 0.31 & 0.35 \\
\hline 60 & 18160.00 & 110.00 & 0.47 & 0.50 & 0.31 & 0.35 \\
\hline 18 & 17400.00 & 122.00 & 0.46 & 0.48 & 0.28 & 0.31 \\
\hline 109 & 17400.00 & 122.00 & 0.46 & 0.48 & 0.28 & 0.31 \\
\hline
\end{tabular}
deviations, are given in Tab. 4.

Tab. 4. Summary similarities of numerical parameters of main propulsion system $(N G)$

The combined similarities of the NG obtained from summation of similarities of numerical and non-numerical

\begin{tabular}{|c|c|c|c|c|c|}
\hline$\frac{\varrho}{\sqrt{n}}$ & 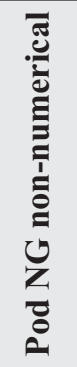 & 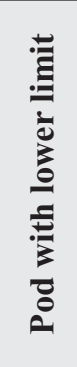 & 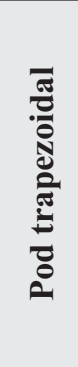 & 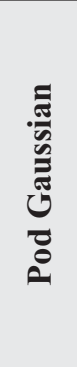 & 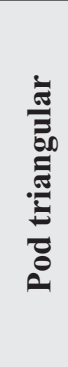 \\
\hline 60 & 0.30 & 0.77 & 0.80 & 0.61 & 0.65 \\
\hline 41 & 0.30 & 0.77 & 0.80 & 0.61 & 0.65 \\
\hline 124 & 0.30 & 0.77 & 0.80 & 0.61 & 0.65 \\
\hline 109 & 0.30 & 0.76 & 0.78 & 0.58 & 0.61 \\
\hline 18 & 0.30 & 0.76 & 0.78 & 0.58 & 0.61 \\
\hline
\end{tabular}
parameters (calculated by using identity test method), are presented in Tab. 5 .

Tab. 5. Combined similarities of main propulsion system (NG)

Values of limit and standard deviations as well as weighing factors are of an example character and have been assumed arbitrarily on the basis of the designer's decision supported by his experience and practice. However the elaborated algorithm for calculation of ship similarity is of a versatile character and can be applied to arbitrary values of design parameters. 


\section{SUMMARY AND CONCLUSIONS}

The functioning of the algorithm was analyzed on the basis of three example cases:

Case 1. Assumed symmetrical values of limit and standard deviations of numerical parameters (ME output power and rotational speed)

Case 2. Assumed greater values of upper limit deviation and upper standard deviation of both parameters in question

Case 3. Assumed symmetrical values of limit and standard deviations of one parameter (ME output power), and smaller values of lower limit and standard deviations, than those of upper ones, of other parameter (ME rotational speed). drawn:

On their basis the following detail conclusions can be

In Case 1 symmetrical values of the limit and standard deviations of the considered numerical parameters (ME output power and rotational speed) were assumed. The applied increase of values of weighing factors of the selected non-numerical parameters (ME number and type) and the simultaneous decrease of values of the weighing factors of the selected numerical parameters, resulted in:

- the increase of values of the summary similarity of the non-numerical parameters,

- the significant decrease of the summary similarity of the numerical parameters as well as the decrease of values of the combined similarity, most in the case of application of the trapezoidal method, and least - in the case of Gaussian method. The same similar ships were searched out.

In Case 2 the assumption of greater values of the upper limit and standard deviations and smaller values of the lower deviations of both selected parameters (ME output power and rotational speed) resulted in a relatively large decrease of the similarity values for all analyzed similarity calculation methods, however it was the greatest in the case of the triangular method, and the least - in the case of Gaussian one. This did not result in a change in searching out similar ships: the same similar ships were found.

In Case 3 where symmetrical values of the limit and standard deviations of one parameter (ME output power) and smaller values of the lower limit and standard deviations, than upper values of other parameter (ME rotational speed), were assumed, the following was observed:

- almost the same decrease of similarity value in the case of application of the trapezoidal and triangular functions,

- the greatest decrease of similarity value in the case of application of Gaussian function,

- no change of similarity value in the case of the function with lower limit. In the Case 1 a greater number of similar ships was selected than in the Case 1 and 2 .

The above presented example cases illustrate that the algorithm is flexible in searching out similar ships. The designer, by choosing values of weighing factors, is capable of searching out ships having one, strictly defined feature, or some purposefully emphasized.

Also, by correcting values of the standard and limit deviations, increasing or decreasing tolerance of calculated results can be achieved.

It is also possible, by proper choice of similarity function, to assess similarity within a given range of values, as well as to obtain distributions of sample size of ships.

\section{BIBLIOGRAPHY}

1. Kowalski Z., Meler-Kapcia M., Zieliński S.: A method for determining similarity of ships in the process of selecting automation systems for power systems (in Polish). Scientific Bulletins of Mechanical Faculty, Koszalin University of Technology, No. 27 (Zeszyty Naukowe Wydz, Mechanicznego Politechniki Koszalińskiej), Mielno 2000.

2. Kowalski Z., Arendt R., Meler-Kapcia M., Zieliński S.: An expert system for aided design of ship systems automation. Expert Systems with Applications, No. 3, Vol. 20, 2001.

3. Kowalski Z., Meler-Kapcia M., Zieliński: Choice of methods for calculation of similarity of ships in aiding ship power plant automation design (in Polish). Proc. of The Technical Scientific Conference „Automation 2000” (Materiały Konferencji Naukowo-Technicznej Automation 2002), PIAP, Warszawa 2002.

4. Lee D., Lee K. H.: An approach to case-based system for conceptual ship design assistent. Expert Systems with Applications, No. 2, Vol. 16, 1999.

5. Meler-Kapcia M, Zieliński S, Kowalski Z.: On application of the Case-Based Reasoning methods in ship automation design. Polish Maritime Research, No. 2, 2003.

6. Meler-Kapcia M., Zieliński S., Kowalski Z.: The aiding of ship power plant automation design by means of CBR method (in Polish). Proc. of The Technical Scientific Conference „Automation 2004” (Materiały Konferencji NaukowoTechnicznej Automation 2004), PIAP, Warszawa 2004.

7. Meler-Kapcia M., Zieliński S., Kowalski Z.: On application of some artificial intelligence methods in ship design. Polish Maritime Research, No.1, 2005.

8. Reich Y, Barai S. V.: A methodology for building neural networks models from empirical engineering data. Engineering Applications of Artificial Intelligence, Vol. 13, 2002.

9. Zbroja S.: Case-Based Reasoning in data and knowledge bases - selected aspects of formal case representation (in Polish). 2nd Domestic Conference on Computer Methods and Systems in Scientific Research and Engineering Design (II Krajowa Konferencja: Metody i systemy komputerowe w badaniach naukowych i projektowaniu inżynierskim). Kraków, October 1999.

\section{CONTACT WITH THE AUTHOR}

Maria Meler-Kapcia, Ph. D.

Faculty of Ocean Engineering and Ship Technology

Gdansk University of Technology

Narutowicza 11/12

80-952 Gdansk, POLAND

e-mail : mariola@pg.gda.pl 